\title{
System Modelling And Analysis Of A Cogeneration Cycle Power Plant Using Graph Theoretic Approach
}

\author{
Nikhil Dev ${ }^{1 *}$, Rajesh Attri ${ }^{1}$, Samsher $^{2}$ \\ ${ }^{1}$ Department of Mechanical Engineering, YMCA University of Science and Technology, \\ Faridabad, Haryana, India \\ ${ }^{2}$ Department of Mechanical Engineering, Delhi Technological University, Delhi, India
}

\begin{abstract}
:
Unit electricity generation cost from an energy resource such as coal with the help of energy conversion systems such as cogeneration cycle power plant (CGCPP) is dependent upon many of the factors such as (a) system structure which is comprised of layout and design (b) system availability which is further dependent upon maintenance (c) power plant thermal efficiency and other regulatory aspects. These are the parameters which are affecting power plant performance. These are numerous in number and nature. For the complete analysis of cogeneration cycle power plant a multi attribute decision making (MADM) technique is required to study the effect of one parameter on the others. In the present analysis a combination of two mathematical tools graph theory and matrix method is used to develop a methodology to evaluate cogeneration cycle power plant performance. The maximum and minimum value of cogeneration cycle power plant performance index is calculated which indicates the range with in which it can vary. This range can be compared with real time value in order asses the relative performance of the system in real time situation.
\end{abstract}

\section{Keywords:}

CGCPP, GTA, Matrix, digraph, graph theory.

\section{INTRODUCTION}

Cogeneration is the production of two or more useful forms of energy (electricity and thermal energy) from the same energy source that is why it is called combined heat and power (CHP) system also. Cogeneration cycle power plant is a very large and complex system comprising of large number of sub-systems. As it is very large system, therefore, its electricity generation capacity is generally in MWs. Large size of power plants are economically viable and cost effective propositions also. Further, pperformance of its components and subsystems are integrated with each other in such a manner that any of its component or system can't be studied without taking the effect of others.

From the literature review, it has been revealed that there are three models i.e. Thermodynamic, thermo-environmental and thermo-economic model for the analysis of cogeneration cycle power plant. Thermodynamic model of a cogeneration cycle power plant gives solution for optimum efficiency or maximum work or both. Thermoeconomic model is useful for the analysis based on efficiency and cost in association with each other. Thermo-environmental models are helpful for the analysis of efficiency in association to environmental loading of the power plant.

DOI : 10.14810/ijmech.2015.4211 
For the systematic, standardized and complete analysis of cogeneration cycle power plant, it is required to develop a methodology based upon multi attribute decision making (MADM) technique. This is required to study the effect of one parameter on the others. Further the technique should be capable of integrating the measurable quantity such as cost and efficiency with virtual quantity such as quality. For this cogeneration cycle power plant thermodynamic, economic, reliability, human being and environment aspects have to be studied independently or in association with each other. At present there is no effective mathematical model for studying these aspects in association with each other for cogeneration cycle power plant. Simple model, easy to implement, lesser computational cost and flexible with changing environment is required to evaluate the cogeneration cycle power plant performance on design basis or analysis basis.

A number of different systematic and practical MADM techniques are suggested in the literature to model various systems and their elements. Such as ISM (interpretive structural modeling) is capable of converting the system structure into a representation which is easy to understand. AHP (analytical hierarchy process) is also capable of decision making when a lot of different options are available with the managers. Graph theory is also one of such methodologies. Graph theory and matrix approach as a decision making method offers a generic, simple, easy, and convenient decision making method that involves less computational efforts in comparison to other similar techniques. Graph theoretic approach (GTA) is a systematic, standardized, easy, and logical approach that has been applied in various fields of science, engineering, economics, management, computer, electrical circuits, physics, chemistry and technology. The matrix approach is useful in analysing the graph models expeditiously to derive the system function and index to meet the objectives. The matrix approach is useful in analyzing the graph/digraph models expeditiously to derive the system function and index to meet the objectives. Moreover, representation of the digraph by a matrix offers ease in computer handling.

Dev et al (2014a) developed a methodology for the analysis of combined cycle power plant performance. The methodology was based upon the combination of graph theory and matrix method. For the performance evaluation CCPP system was divided into six sub-systems. These sub-systems were developed in such a way that all of them were interdependent.

In literature it is also reported that the system structure developed for the performance evaluation can be extended for the evaluation of other performance parameters also. The methodology developed for performance evaluation was extended for the evaluation of reliability and efficiency. Dev et al (2014a) proposed that reliability is dependent upon the sub-systems. It is the reliability of individual components which affect the reliability of macro-system. Therefore, it is rudiment to consider all of the sub-systems while evaluating the reliability of any system. In that work the methodology was explained with the help of two examples. In those examples it was demonstrated that how the effect of environment could be incorporated in the system.

For a power generation unit efficiency is one of the foremost criteria of efficiency evaluation. Dev et al (2015c) developed a methodology for the efficiency evaluation and methodology was based upon the GTA and matrix method. In that work the results obtained with graph theoretic methodology were in line with the thermodynamic analysis. As the efficiency and reliability both were calculated with the help of same methodology, therefore, it was possible to integrate the results obtained for the efficiency and reliability. As a result a common methodology was proposed for the efficiency and reliability evaluation. 
Graph theory has been utilized for the analysis of different kind of systems. Dev et al (2012, 2014b) utilised the GTMM for the analysis of cogeneration cycle power plant also. Efficiency and reliability for the cogeneration cycle power plant was evaluated with the help of this methodology. In view of these advantages, GTA method is proposed in this paper for the prediction of performance of a cogeneration cycle power plant by taking into account the performance of its four systems, i.e. the air compressor, combustion chamber, gas turbine and heat recovery steam generation (HRSG) and the interactions between various systems. These system divisions are based upon the working of the power plant which is further dependent upon the type of components and equipment's present in the system. These systems are interlinked to each other and it is established to achieve better efficiency, reliability and maintainability. The performance of the macro system i.e. cogeneration cycle power plant is dependent upon these four sub-systems. Therefore, the methodology is developed in such a way that all of the sub-systems are incorporated in the modelling.

\section{SYSTEM STRUCTURE ANALYSIS OF COGENERATION CYCLE POWER PLANT}

System structure modeling of cogeneration cycle power plant which is to be analysed is described in this section. This is the working of the four of its sub-systems. These sub-systems are the integral part of the macro system and none of them is not independent. The dependency of one system on the other is due to the technology of energy conversion adopted by the power plant organisation. Cogeneration cycle power plant and its components considered for the present analysis is shown in Figure 1.

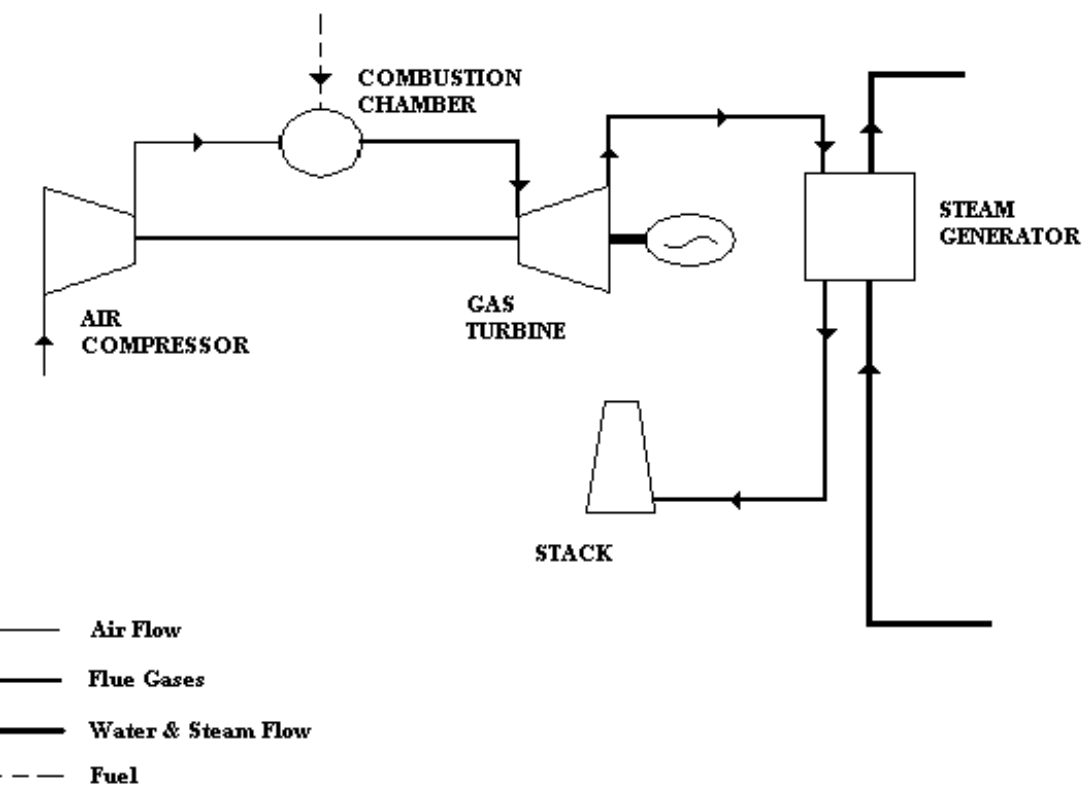

Figure 1. Schematic flow diagram of cogeneration Cycle Power Plant

The humid air at the ambient temperature and pressure (NTP) enters the air compressor after being filtered in the air filtration system. In the filteration system dust particles are removed and humidity of the air remains unaffected. In the market different sort of filters are available for filtering different impurities. Filtered air which is comparatively pure and humidified is 
compressed by the air compressor and directed to the combustion chamber. Due to the compression temperature and pressure of the air is increased. In combustion chamber compressed air which is at high temperature and pressure is mixed with the natural gas (CNG). Natural gas is supplied from the fuel supply system to produce hot combustion flue gas in the combustor. This hot combustion flue gas at high temperature and pressure is delivered to the gas turbine with the help of transfer port where the power is generated. Gas turbine is the only power generating system in this system. Therefore, the power to compress the air in air compressor system is also extracted from the gas turbine.

When the flue gases are coming out of air compressor they are still at high temperature. If these are sent to the environment then it will be a waste. Therefore, a system known as waste heat recovery boiler is installed to expedite the full potential of flue gases. The exhaust gases are transferred to environment after passing a series of tubes. These tube arrangement is heat recovery steam generation system. Here water is converted into steam after obtaining the heat from flue gases. The steam produced in this way is at low temperature and it is used as process steam. This is the very basic description of the cogeneration cycle power plant system structure. Based upon this description cogeneration cycle power plant is divided into following four systems:

1. Air compressor system $\left(\mathrm{S}_{1}\right)$

2. Combustion chamber system $\left(\mathrm{S}_{2}\right)$

3. Gas turbine system $\left(\mathrm{S}_{3}\right)$

4. Heat Recovery Steam Generator system $\left(\mathrm{S}_{4}\right)$

All of these four systems are connected to each other directly or indirectly. System structure is to be converted into digraph representation for the GTA. Digraph is a standard mathematical representation and it is being used by from last many centuries. It is a representation helpful for understanding of the system structure. In GTA system structure development is first step and the success of the model developed is very much dependent upon this. Henceforth development of the digraph is described.

Digraph is the combination of vertices and edges. This is used to represent the system in pictograph. These types of representation are suitable to represent all of the systems and their interdependencies. Its construction is also very easy and logical. In a digraph edges represents the interlinking and vertices represents the system characteristic. Characteristic may be reliability, efficiency, maintainability, cost etc. Let each one of the four systems of cogeneration cycle power plant is represented by vertices name $S_{i}$ 's $(i=1,2,3,4)$ and interconnection between two systems $\left(S_{i}\right.$, $\left.S_{j}\right)$ is represented by edges naming as $c_{i j}$ 's $(i=1,2,3,4)$ connecting the two vertices naming $S_{i}$ and $S_{j}$ then the digraph for the system structure of the Figure 1 will be as represented in Figure 2. 

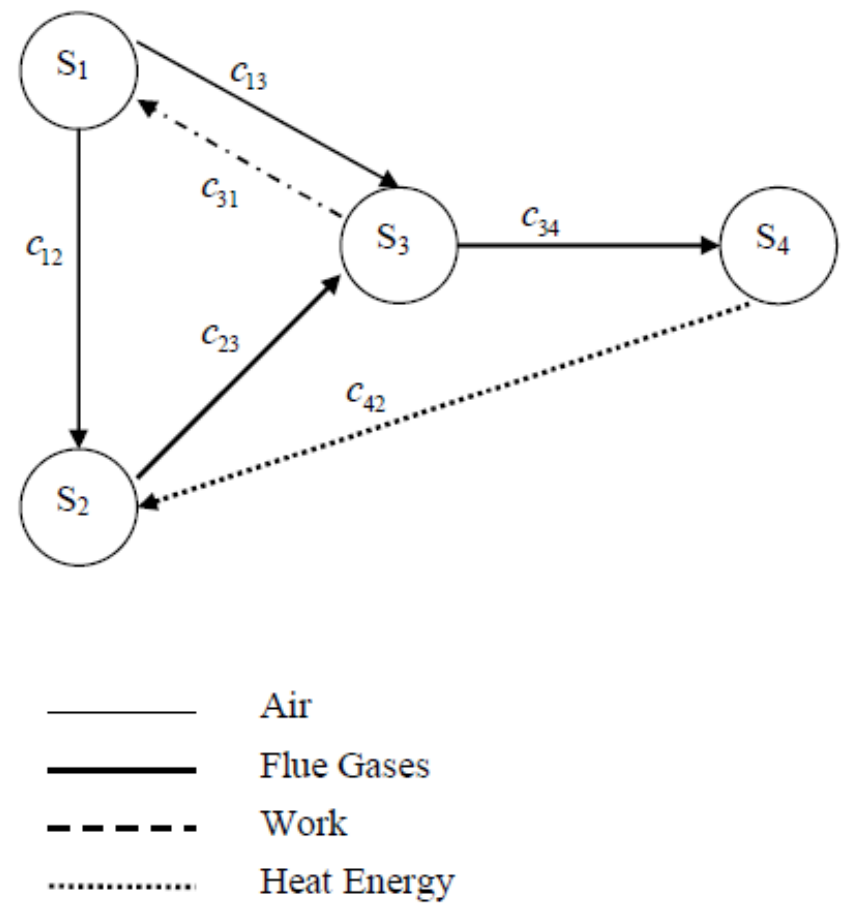

Figure 2. System structural graph of cogeneration cycle power plant: Air compressor system $\left(\mathrm{S}_{1}\right)$, Combustion chamber system $\left(\mathrm{S}_{2}\right)$, Gas turbine system $\left(\mathrm{S}_{3}\right)$, Heat Recovery Steam Generator system $\left(\mathrm{S}_{4}\right)$

This is based upon the working of cogeneration cycle power plant as per the following:

1. The ambient air at normal temperature, humidity and pressure comes to air compressor after being filtered by air filters. Compressor and turbine are attached to each other with a solid shaft. Therefore, the mechanical power to compress the air comes to air compressor from gas turbine section. In the digraph it is represented by the edge name $c_{31}$. $S_{1}$ is the air compression system.

2. After compression in air compressor it goes to the combustion chamber. Fuel is added in the combustion chamber in the compressed air. In the digraph it is represented by edge name $c_{12}$. This fuel air mixture is ignited with the help of electrodes.

3. A gas turbine blade is cooled by being made hollow from inside so that a coolant air can circulate through it. This type of cooling arrangement is designed for the first two stages. Coolant air is obtained directly from the compressor and it is cooled due to expansion. The presence of the edge $c_{13}$ represents the bypass cooling air.

4. Fuel supplied to CC (combustion chamber) is generally in gaseous form and it is compressed natural gas $(\mathrm{CNG})$. Sometimes liquid fuel can also be supplied. For the comparative efficiency analysis fuel unit calorific value $(\mathrm{CV})$ is more suitable criteria in comparison to its hydrocarbon composition. Fuel supply is to be maintained constantly without fail otherwise plant will be shut off. Outlet temperature and pressure of combustion chamber system $\left[\mathrm{S}_{2}\right]$ 
depends upon thermal stress limit of gas turbine blade material and it is improved year by year. Combustion chamber product that is flue gas flows to gas turbine system as shown by edge naming $\mathrm{c}_{23}$.

5. Depending upon the temperature and pressure of flue gas, heat recovery system for steam generation $\left[\mathrm{S}_{4}\right]$ may be used for (i) partial or complete heating (regeneration) of the pressurized air leaving the compressor and represented by the edge naming $\left(\mathrm{c}_{42}\right)$, (ii) generation of steam in a dual steam cycle.

6. Flue gases which are the product of $\mathrm{CC}$ enter to heat recovery system for steam generation naming $\left[\mathrm{S}_{4}\right]$ are shown by the edge $\mathrm{c}_{34}$.

The system structure graph as represented in (Figure 2) represents the internal structure of the cogeneration cycle power plant at system level. It shows different systems and their interconnections in the cogeneration cycle power plant as discussed above.

\section{GRAPH THEORETIC APPROACH}

Graph theoretic analysis (GTA) is a three step systematic and logical methodology which is capable of converting qualitative value factors to quantitative values and mathematical modeling gives an edge to the proposed technique over conventional methods like cause-effect diagrams, flow charts etc. Graph theory serves as a mathematical model of any system that includes multirelations among its constituent elements because of its diagrammatic representations and esthetic aspects (Jangra et al 2011; Raj and Attri, 2010; Gandhi et al 1991; Grover et al 2006; Mohan et al 2008; 2004; Rao, 2004; 2006; Rao and Gandhi, 2001; Rao and Padmanabham, 2006; Tang, 2001; Venkataswamy and Agarwal, 1997; Wani and Gandhi, 1999; Attri et al. 2013; 2014; Dev and Attri 2013; Dev et al. 2012; 2013a; 2013b; 2014a; 2014b; 2015a; 2015b; 2015c). In the literature the standardized procedure of GTA is comprised of three steps. Henceforth these are developed for the cogeneration cycle power plant analysis.

\subsection{Digraph Development and Representation}

A cogeneration cycle power plant performance digraph is developed to represent the effect of one system on the others in terms of nodes and edges. This is form of graph in which system characteristic is represented in the roundels and these roundels are connected with arrows. Therefore, digraph consists of a set of nodes $S=\left\{S_{i}\right\}$ with $i=1,2, \ldots, N$ and a set of directed edges $E=\left\{c_{i j}\right\}$. Although the edges may be non-directed in some cases. A node $S_{i}$ represents $i^{\text {th }}$ parameter/system and edges represent the interdependence between parameters. The total of nodes, $N$, is equal to the number of parameters considered for the system.

In particular four systems are identified form the cogeneration cycle power plant performance digraph. If all the four systems of cogeneration cycle power plant are linked to each other then digraph for the cogeneration cycle power plant will be as shown in Figure 3. 


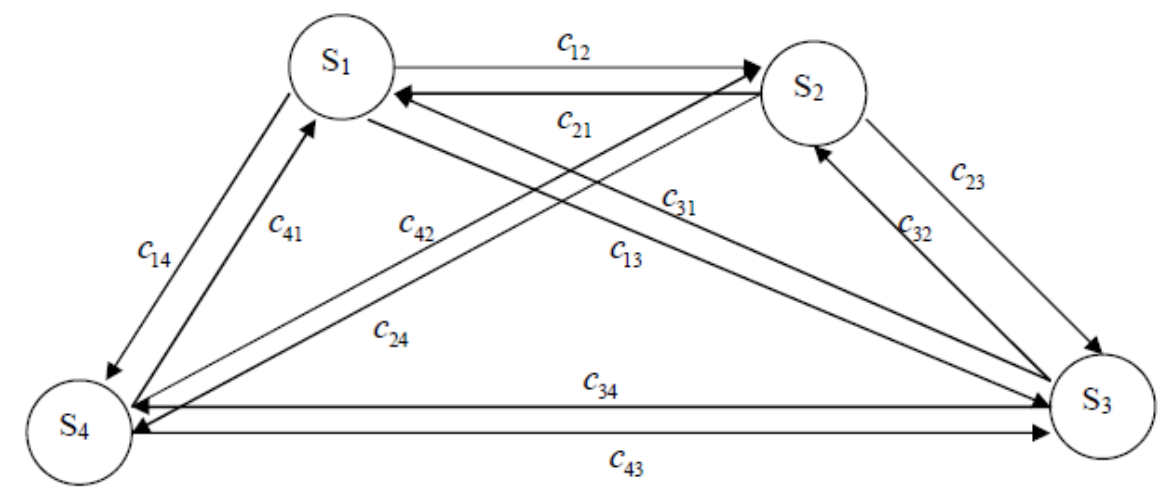

Figure 3. Digraph showing six attributes of Cogeneration Cycle Power Plant and their interdependencies in the system (attributes: Air compressor system $\left(\mathrm{S}_{1}\right)$, Combustion chamber system $\left(\mathrm{S}_{2}\right)$, Gas turbine system $\left(\mathrm{S}_{3}\right)$, Heat Recovery Steam Generator system $\left(\mathrm{S}_{4}\right)$ )

Graph theoretic analysis and representation permits the incorporation or deletion of any interconnection, inheritance or system in digraph representation. This makes it more attractive for real time analysis. This presentation makes the strong base for computer processing with the help of matrix representation.

\subsection{Matrix Representation}

A digraph is such a representation which is easy to convert into matrix representation. Matrix representation of a digraph gives more elaboration to digraph so that it represents itself in computational form. For a general case with n systems, in that case it will be represented as:

$$
E=\left[\begin{array}{cccccc}
i & j & k & - & m & { }^{n} \text { Systems } \\
S_{i} & c_{i j} & c_{i k} & -- & c_{i m} & c_{i n} \\
c_{j i} & S_{j} & c_{j k} & -- & c_{j m} & c_{j n} \\
c_{k i} & c_{k j} & S_{k} & -- & c_{k m} & c_{k n} \\
-- & -- & -- & -- & -- & -- \\
c_{m i} & c_{m j} & c_{m k} & -- & S_{m} & c_{m n} \\
c_{n i} & c_{n j} & c_{n k} & -- & c_{n m} & S_{n}
\end{array}\right]--
$$

The diagonal elements represent the contribution of systems in cogeneration cycle power plant performance. It is known as system inheritance. It is different for different systems. The off diagonal elements represent interdependencies of each system with other systems. This form of matrix is also known as variable permanent matrix (VPM).

\subsection{Permanent Function Development and Representation}

It is stated earlier that GTA is three step analysis and permanent function development and representation is last step of the process. The combination of digraph and matrix representation is changed by changing the labels of their nodes but the basic idea of representation remains the 
same. Research is a continuous process and to resolve this issue permanent function representation of matrix in expression (1) inserted. The permanent function development and representation is standardized expansion of matrix function in combinatorial mathematics (Deo, 2007). The permanent function representation and development is obtained in a similar manner as the determinant representation. But unlike in a determinant representation and development where negative sign appears alternatively due to Lagrange's expansion, in a variable permanent function positive signs replace with all these negative signs.

Permanent Function developed for a general case such as matrix expression (1)) is as written in the expression (2) represented below.

$$
\begin{aligned}
& \operatorname{Per}(E)=\prod S_{i}+\sum_{i} \sum_{j} \sum_{k} \ldots . . \sum_{m} \sum_{n} c_{i j}^{2} S_{k} S_{l} S_{m} S_{n} \ldots .+2 \sum_{i} \sum_{j} \sum_{k} \ldots \ldots \sum_{m} \sum_{n}\left(c_{i j} c_{j k} c_{k i}\right) S_{l} S_{m} S_{n} \ldots \\
& +2 \sum_{i} \sum_{j} \sum_{k} \ldots . . \sum_{m} \sum_{n}\left(c_{i j} c_{j k} c_{k l} c_{l i}\right) S_{m} S_{n} \ldots .+\sum_{i} \sum_{j} \sum_{k} \ldots . . \sum_{m} \sum_{n}\left(c_{i j}^{2} c^{2}{ }_{i j}\right) S_{m} S_{n} \ldots . \\
& +2 \sum_{i} \sum_{j} \sum_{k} \ldots . . \sum_{m} \sum_{n}\left(c_{i j} c_{j k} c_{k l} c_{l m} c_{m i}\right) S_{n} \ldots+2 \sum_{i} \sum_{j} \sum_{k} \ldots . . \sum_{m} \sum_{n}\left(c_{i j} c_{j k} c_{k i}\right) c_{l m}^{2} S_{n} \ldots . \\
& +\sum_{i} \sum_{j} \sum_{k} \ldots . . \sum_{m} \sum_{n}\left(c_{i j}^{2}\right)\left(c^{2}{ }_{k l}\right)\left(c^{2}{ }_{m n}\right) \ldots .+4 \sum_{i} \sum_{j} \sum_{k} \ldots . . \sum_{m} \sum_{n}\left(c_{i j} c_{j k} c_{k i}\right)\left(c_{l m} c_{m n} c_{l n}\right) \ldots \\
& +2 \sum_{i} \sum_{j} \sum_{k} \ldots . . \sum_{m} \sum_{n}\left(c_{i j} c_{j k} c_{k l} c_{l i}\right)\left(c_{m n}^{2}\right) \ldots . .
\end{aligned}
$$

\subsection{Cogeneration Cycle Power Plant Performance Index}

It is discussed earlier that there are four major systems in cogeneration cycle power plant. These systems are interconnected with each other. The output of system is the input for the other. Therefore, these are linked to each other. If the performance of one system is deteriorated then other systems will also be affected. It is supposed that every system is performing its best at the time of installation. With the passage of time performance of system is deteriorated. Degradation of the variable varies from system to system. This is also to be quantified. Quantification is one of the time consuming process of GTA. cogeneration cycle power plant performance index is function of considered systems i.e. air compressor system, heat recovery system for steam generation, combustion chamber system, gas turbine system. In mathematical form, it is represented as:

Cogeneration cycle power plant performance index (CGCPPPI) $=f($ systems $)$

$=f$ (Air compressor system, Heat recovery system for steam generation, Combustion chamber system, Gas turbine system)

The permanent function of cogeneration cycle power plant system (i.e. equation (3)) is proposed, here, for the evaluation of cogeneration cycle power plant PI because it contains all the possible components of cogeneration cycle power plant system and their interdependence.

The main features of cogeneration cycle power plant Performance evaluation index (cogeneration cycle power plant I) are as follows:

1. The index value is to represent the performance of existing cogeneration cycle power plant. If the index value is higher than plant performance is better. A lower value indicates that there is more scope of improvement. 
2. The value of index may be used for self-analysis of a cogeneration cycle power plant. Higher value of evaluation index indicates that an organization has to improve the weak links of power plant.

3. Index value may be used for the comparison of similar cogeneration cycle power plants. Performance is represented in evaluation index form. All of the power plants under consideration will be having some index value. Higher value of evaluation index means better performance.

To calculate this performance evaluation index, the values of inheritance and interdependencies which are $S_{i}$ and $c_{i j}$ are required. These are the quantified values obtained from experienced personals for the inheritance and interlinking. The values of the parameters and their interdependence mentioned in this work are found and calculated on the basis of data available in the organisation (industry or academic) and the experience of production/generation personnel. In the data acquisition maintenance personal may play a major role if followed properly. As the system performance is deteriorated, maintenance personals decide about the preventive or corrective maintenance. It is the performance of the system or equipment which gives an indication about the preventive action execution. Therefore, a base line may be selected so that maintenance may be carried out.

Sometimes it is observed that quantitative value is not available, then comparatively ranked value on a stanine scale (e.g., from 1 to 9 ) is adopted. Table 1 is suggested for this purpose. To assign numerical values to the interdependence of parameters $c_{i j}$, the opinions of production experts can be recorded. Qualitative values of the interdependence of parameters mentioned in this work is assigned on a scale (e.g., 1 to 5), as suggested in Table 2.

Table 1. Quantification of factors affecting cogeneration cycle power plant performance

\begin{tabular}{|c|c|c|}
\hline S. No. & $\begin{array}{l}\text { Qualitative measure of factors at sub- } \\
\text { system level affecting cogeneration cycle } \\
\text { performance }\end{array}$ & $\begin{array}{l}\text { Assigned value of } \\
\text { factors at } \text { sub-system } \\
\text { level } S_{i}\end{array}$ \\
\hline 1 & Exceptionally low & 1 \\
\hline 2 & Very Low & 2 \\
\hline 3 & Low & 3 \\
\hline 4 & Below average & 4 \\
\hline 5 & Average & 5 \\
\hline 6 & Above Average & 6 \\
\hline 7 & High & 7 \\
\hline 8 & Very High & 8 \\
\hline 9 & Exceptionally High & 9 \\
\hline
\end{tabular}


International Journal of Recent advances in Mechanical Engineering (IJMECH) Vol.4, No.2, May 2015

Table 2. Quantification of interdependencies

\begin{tabular}{clc}
\hline S. No. & Qualitative measure of interdependencies & $\mathbf{c}_{\mathbf{i j}}$ \\
\hline 1 & Very Strong & 5 \\
2 & Strong & 4 \\
3 & Medium & 3 \\
4 & Weak & 2 \\
5 & Very weak & 1 \\
\hline
\end{tabular}

\section{DEVELOPMENT OF GRAPH THEORETIC MODEL OF COGENERATION CYCLE POWER PLANT}

The graph theoretical methodology combines various attributes relevant to a thermal power plant performance into a single measure so that a comprehensive ranking of the two or more plants could be made on the basis of their performance. Cogeneration cycle power plant being very large and complex system has to be divided in to small systems and no system should be independent. Inheritance of every system and their interdependency decides the value of cogeneration cycle power plant performance evaluation index. In the following section, system structure modeling of cogeneration cycle power plant and its graph theoretic analysis is described.

\subsection{Digraph Representation of CGCPP system}

Digraph is used to represent the factors/systems and their interdependencies in terms of nodes and edges. $S_{i j}$ indicates degree of dependence of $j^{\text {th }}$ factor/system on the $i^{\text {th }}$ factor/system. In the digraph $S_{i j}$ is represented as a directed edge from node $i$ to node $j$. The digraph permits to analyse cogeneration cycle power plant performance and gives a feeling of interactions between the systems. It is to be mentioned at this point that roundel size and line length may be selected as per the convenience of the researcher. It is independent of the inheritance and interlinking evaluation. There is no such direction in literature about the angle of lines also. Digraph for the cogeneration cycle power plant discussed above is shown in Figure 4.

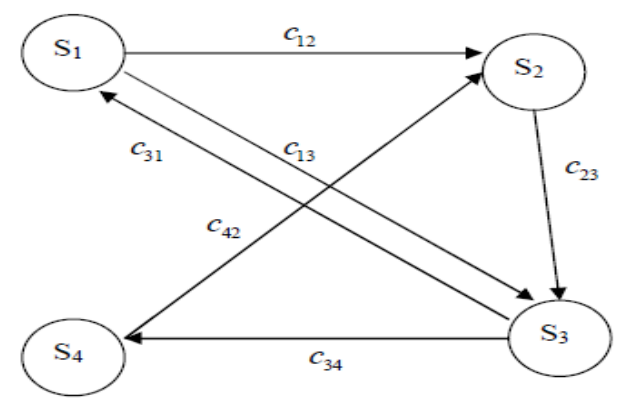

Figure 4. Digraph showing six attributes of Cogeneration Cycle Power Plant and their interdependencies in the system (attributes: Air compressor system $\left(S_{1}\right)$, Combustion chamber system $\left(S_{2}\right)$, Gas turbine system $\left(\mathrm{S}_{3}\right)$, Heat Recovery Steam Generator system $\left(\mathrm{S}_{4}\right)$ ) 


\subsection{Variable permanent system structure matrix (VPSSM) for a CCPP}

In order to obtain proper characterization of cogeneration cycle power plant systems as derived from combinatorial considerations, a variable permanent matrix, also known as the permanent function, is proposed. Use of this concept in system structure modeling helps in retaining the structural information of the system.

For the system under consideration (cogeneration cycle power plant in this case), corresponding to Figure 4, variable permanent structure matrix $\left(\mathrm{T}_{\mathrm{c}}\right)$ can be written as:

$$
\begin{aligned}
& \begin{array}{lllll}
1 & 2 & 3 & 4 & \text { Systems }
\end{array} \\
& T_{c}=\left[\begin{array}{cccc}
S_{1} & c_{12} & c_{13} & 0 \\
0 & S_{2} & c_{23} & 0 \\
c_{31} & 0 & S_{3} & c_{34} \\
0 & c_{42} & c_{43} & S_{4}
\end{array}\right] \quad \begin{array}{l}
1 \\
2 \\
3
\end{array}
\end{aligned}
$$

\subsection{Permanent representation of system structure matrix (VPSSM) for a CCPP}

The permanent of VPSSM is also known as variable permanent system structure function and it is dependent upon the presence of loops and dyads. Permanent Function for cogeneration cycle power plant of matrix expression (3) is developed and represented as per the literature of Jurkat and Ryser (1966) formula as:

$$
\operatorname{Per}\left[T_{c}\right]=\left[S_{1} S_{2} S_{3} S_{4}+\left(c_{13} c_{31}\right)\left(\mathrm{S}_{2} \mathrm{~S}_{4}\right)+\left(c_{31} c_{23}\right)\left(\mathrm{S}_{1} \mathrm{~S}_{4}\right)+\left(c_{34} c_{43}\right)\left(\mathrm{S}_{1} \mathrm{~S}_{2}\right)+\mathrm{S}_{1}\left(c_{23} \mathrm{c}_{34} c_{42}\right)\right]
$$

Every term in the Per $\left[\mathrm{T}_{\mathrm{c}}\right]$ is representing the part of the system and interlink. For example the $\mathrm{S}_{1} \mathrm{~S}_{2} \mathrm{~S}_{3} \mathrm{~S}_{4}$ shows that all four systems are linked to each other. It represents that for a cogeneration cycle power plant system to work all of the systems should be working. Any of the system cannot be omitted. In the similar manner other terms also carry information regarding the loops and dyads present in the system.

\section{EXAMPLE}

For demonstration the proposed methodology, a cogeneration cycle power plant is taken as an example. It is proposed to find the value of cogeneration cycle power plant performance evaluation index. For determining the evaluation index we require numerical values of inheritance of all systems and their interdependencies, i.e. in VPM-s for cogeneration cycle power plant (equation (3)). Step by step methodology discussed in the previous section is used to evaluate cogeneration cycle power plant performance evaluation index in this example.

Step 1: Various systems (four systems in the present case) affecting the cogeneration cycle power plant performance are identified, as shown in Figure 3. 
Step 2: A digraph is developed for these four systems, as shown in Figure 4. The dependencies of systems are visualized through the digraph.

Step 3: The variable permanent matrix is developed for the cogeneration cycle power plant system. The inheritance of systems and their interdependencies are discussed with experts as per table 1 and 2.

Step 4: The value of permanent function (cogeneration cycle power plant performance evaluation index) is calculated. It is suggested to find hypothetical best and hypothetical worst value of cogeneration cycle power plant performance evaluation index.

Cogeneration cycle power plant performance evaluation index is at its best when the inheritance of all its systems is at its best. Maximum value of Per $\left[\mathrm{T}_{c}\right]$ is obtained when inheritance of all systems is maximum, i.e. value taken from Table 1 is 9 . The values of off diagonal elements are taken from Table 2 as explained below:

- Performance of air compressor system has a direct effect on the performance of combustion chamber system and that is why edge naming $c_{12}$ is assigned a value of 5 .

- Compressed air from the compressor is sent to the gas turbine for the cooling of gas turbine blades. This cooling air decreases the temperature of the combustion gases in the gas turbine. Their effect is not much pronounced and hence edge naming $\mathrm{c}_{13}$ is assigned with the value of 3 .

- Gas turbine and air compressor is attached with other and power to drive the compressor comes from the turbine. But there is no power transfer from combustion chamber to the air compressor. So edge naming $c_{21}$ is assigned value 0 and edge naming $c_{31}$ as 3 . After combustion in combustion chamber flue gases enter the gas turbine. As the performance of gas turbine is dependent upon the condition of flue gases coming out of combustion chamber and gas turbine efficiency, a value of 5 is given to edge naming $c_{23}$.

- As heat recovery system for steam generation is at the outlet of gas turbine its performance is more affected by the gas turbine than combustion chamber. Due to this reason edge naming $\mathrm{c}_{34}$ is given a value of 4 and edge naming $\mathrm{c}_{42}$ is with 2 .

Thus, equation (9) may be written for the maximum value of $\operatorname{Per} T_{c}$ as

$$
T_{1}=\left[\begin{array}{llll}
9 & 5 & 3 & 0 \\
0 & 9 & 5 & 0 \\
3 & 0 & 9 & 4 \\
0 & 2 & 0 & 9
\end{array}\right]
$$

The value of permanent of the above function is 8325 , i.e. maximum Per $T_{c}=8325$.

Similarly cogeneration cycle power plant performance evaluation index is at its worst when the inheritance of all its systems is at its worst i.e. value taken from Table 1 is 1 .

Thus, equation (9) may be rewritten for the minimum value of $\operatorname{Per} T_{c}$ as 
International Journal of Recent advances in Mechanical Engineering (IJMECH) Vol.4, No.2, May 2015

$$
T_{2}=\left[\begin{array}{llll}
1 & 5 & 3 & 0 \\
0 & 1 & 5 & 0 \\
3 & 0 & 1 & 4 \\
0 & 2 & 0 & 1
\end{array}\right]
$$

The value of permanent of the above function is 125 , i.e. minimum Per $T_{c}=125$.

The value of Per $T_{c}$ indicates the value of cogeneration cycle power plant performance evaluation index. Thus, the maximum and minimum value of performance evaluation index indicates the range with in which it can vary. Experts can use this range to decide a threshold value for a given set of similar power plant.

Monitoring at regular interval may be carried out by third party to assess power plant performance. Moreover, the values may be carried out at regular interval for the assessment of power plant performance.

\section{Conclusion}

It is the objective of any analysis that it must specify results in accordance to the real time condition. In the present work also a methodology is proposed which is capable of interpreting the results in accordance with the real time operating power plant. Power plants are available with a large number of configurations. The methodology developed in the present work is capable of analyzing the different kinds of the power plants.

Power generation industry is growing at a very fast rate and it is much more in the developing countries like India. For the methodology of analysis it is also expected that results should come out in a cost effective manner. GTA is a three step approach. These steps are very easy to understand and their implementation is also standardized. Due to this reason it is very much cost effective and time consumption for the analysis is also very less.

The success of the results obtained with GTA is dependent upon the accuracy of the quantification. The quantification accuracy is further dependent upon the expert advise available with the decision maker. Decision maker is required to collect a large quantity of data for better accuracy of the results. Therefore, the methodology based upon GTA is practical and capable of analyzing real time power plant. 
International Journal of Recent advances in Mechanical Engineering (IJMECH) Vol.4, No.2, May 2015

\section{References}

[1] Attri, R., Dev, N. \& Sharma, V. (2013). Graph Theoretic approach (GTA) - A Multi-Attribute Decision Making (MADM) Technique. Research Journal of Engineering Sciences, 2(1), 50-53.

[2] Attri, R., Grover, S. \& Dev, N. (2014). A graph theoretic approach to evaluate the intensity of barriers in the implementation of Total Productive Maintenance (TPM). International Journal of Production Research, 52(10), 3032-3051.

[3] Deo, N. (2007). Graph theory with applications to engineering and computer science. Prentice Hall of India, New Delhi.

[4] Dev, N., Samsher, Kachhwaha, S. S. \& Attri, R. (2012). GTA based frame work for evaluating the role of design parameters in Cogeneration Cycle Power plant efficiency. Ain Shames Engineering Journal, 4(2), 273-284.

[5] Dev, N. \& Attri, R. (2013). System modelling and analysis of a Gas turbine power plant using graph theoretic approach. International Journal of Energy, Environment and Economics, 21(1), 21-33.

[6] Dev, N., Attri, R., Sharma, V. \& Kumar, K. (2013a). Economic analysis of a cogeneration cycle power plant. International Journal of Management and Behavioural Sciences. 4, 184-189.

[7] Dev, N., Attri, R., Sharma, V. \& Rana, A. (2013b). Development of graph theoretic model for economic analysis of combined heat and power system. International Journal of Management and Behavioural Sciences. 4, 166-174.

[8] Dev, N., Samsher, Kachhwaha, S. S. \& Attri, R. (2014a). Development of reliability index for combined cycle power plant using graph theoretic approach. Ain Shames Engineering Journal, 5(1), 193-203.

[9] Dev, N., Samsher, Kachhwaha, S. S. \& Attri, R. (2014b). Development of reliability index for cogeneration cycle power plant using graph theoretic approach. International Journal of Systems Assurance Engineering and Management, 5(4), 700-710.

[10] Dev, N. \& Attri, R. (2015a). Analysis of Barriers to World Class Manufacturing Using Graph Theory. Proceedings of Twelfth AIMS International Conference on Management, 1319-1327.

[11] Dev, N. \& Attri, R. (2015b). Site Selection for a Power Plant Using Graph Theory and Matrix Method. Proceedings of Twelfth AIMS International Conference on Management, 1328-1335.

[12] Dev, N., Samsher, Kachhwaha, S. S. \& Attri, R. (2015c). GTA modeling of combined cycle power plant efficiency analysis. Ain Shames Engineering Journal, 6(1), 217-237.

[13] Gandhi, O. P., Agrawal, V. P. \& Shishodia, K. S. (1991). Reliability analysis and evaluation of systems. Reliability Engineering and System Safety. 32, 283-305.

[14] Grover, S., Agrawal, V. P. \& Khan, I. A. (2006). Role of human factor in TQM: a graph theoretic approach. Benchmarking: An International Journal, 13(4), 447-468.

[15] Jangra, K., Grover, S., Chan, F. T. S. \& Aggarwal, A. (2011). Digraph and matrix method to evaluate the machinability of tungsten carbide composite with wire EDM. International Journal of Advanced Manufacturing Technology. 56, 959-974.

[16] Jense, J. B. \& Gutin, G. (2000). Digraph theory, algorithms and applications. Springer

[17] Jurkat, W. B. \& Ryser, H. J. (1966). Matrix factorisation of determinants and permanents. Journal of Algebra. 3, 1-11.

[18] Mohan, M., Gandhi, O. P. \& Agrawal, V. P. (2004). Maintenance strategy for a coal based steam power plant equipment - a graph theoretic Approach. Proceedings of the Institution of Mechanical Engineers, Part A: J. Power and Energy, 218, 619-636.

[19] Mohan, M., Gandhi, O. P. \& Agrawal, V. P. (2008). Real time reliability index of steam power plant a systems approach. Proceedings of the Institution of Mechanical Engineers, Part A: J. Power and Energy, 220, 355-369.

[20] Raj, T. \& Attri, R. (2010). Quantifying barriers to implementing Total Quality Management (TQM). European Journal of Industrial Engineering. 4(3), 308-335.

[21] Rao, R. V. (2004). Digraph and matrix methods for evaluating environmentally conscious manufacturing programs. International Journal of Environmentally Conscious Design and Manufacturing. 12, 23-33. 
[22] Rao, R. V. (2006). A decision-making framework model for evaluating flexible manufacturing systems using digraph and matrix methods. International Journal of Advanced Manufacturing Technology. 30(11-12), 1101-1110.

[23] Rao, R.V. \& Gandhi, O. P. (2001). Digraph and matrix method for selection, identification and comparison of metal cutting fluids. Proceedings of the Institution of Mechanical Engineers, Part J, Journal of Engineering Tribology. 212, 307-318.

[24] Rao, V. R. \& Padmanabhan, K. K. (2006). Selection, identification and comparison of industrial robots using digraph and matrix methods. Robotics Computer-Integrated Manufacturing. 22(4), 373-383.

[25] Tang, J. (2001). Mechanical system reliability analysis using a combination of graph theory and Boolean function. Reliability Engineering and System Safety. 72, 21-30.

[26] Venkataswamy, R. \& Agrawal, V. P. (1997). A digraph approach to quality evaluation of an automatic vehicle. Quality Engineering. 9(3), $405-417$.

[27] Wani, M. F. \& Gandhi, O. P. (1999). Development of maintainability index for mechanical systems. Reliability Engineering and System Safety. 65, 259-270. 